SPECIAL ISSUE

\title{
Education and Training for Ethical Practice of Telemedicine for Registered Medical Practitioners in India
}

\author{
Sunil Shroff'*, Bagmisikha Puhan², Lavanian Dorairaj ${ }^{3}$, Mayank Agarwal' ${ }^{4}$, Manick Rajendran ${ }^{5}$, \\ Ravi Modali', Suchitra Mankar ${ }^{7}$, Permachanahalli Sachidananda Ramkumar ${ }^{8}$ and Sandeep Patil ${ }^{9}$ \\ 'President,TN-Telemedicine Society of India, Chennai, India; ${ }^{2}$ Associate Partner,TMT Law Practice, Legal Advisor - \\ Telemedicine Society of India, New Delhi, India; ${ }^{3}$ Director, LYNK AmbuPod Pvt Ltd, Bengaluru, India; ${ }^{4}$ Founder, vCliniq, \\ New Delhi, India; ${ }^{5}$ Founder \& CEO, iMMi Life Healthcare, Chennai, India; ${ }^{6}$ Executive Committee Member, Indian Society \\ of Lifestyle Medicine, Bengaluru, India; 7 Founder-Director, Doorstep Health Services Pvt Ltd, Pune, India; ${ }^{8}$ Director, \\ Applied Cognition Systems Pvt, Bengaluru, India; ${ }^{9}$ Executive Director, Applied Cognition Systems, Bengaluru, India
}

\section{Abstract}

The Telemedicine Practice Guidelines (TPG) released in 2020 provide legal framework for registered medical practitioners (RMPs) to consult with patients deploying Information and Communication Technology. Necessary compliance requirements have also been included. This article analyses the effectiveness of the 'Train to Practice' course designed by the Telemedicine Society of India to train doctors in India to follow ethical and safe standards of practice of telemedicine. The online course was taught by a faculty of 18 members, over a period of 6 months using four modules.

The course comprised of a pre-course assessment, live lectures, and a post-course assessment to ascertain the level of preparedness and knowledge imparted to the RMPs by way of the course. The article highlights that the RMPs had a preliminary understanding of the concept of telemedicine prior to the course. Post-course assessment indicated improvement in knowledge levels. Pre- and post-course assessments were conducted using multiple choice Yes or No response-based questionnaires.

Participating RMPs exhibited a real drive to understand the legalities and operational procedures of the practice of telemedicine as was evidenced by queries posed to the lecturers. While the course was rated generously by all the attendee RMPs, there were also evidences of a lack of seriousness from certain RMPs who did not have to pay for participating in the course. The researchers have also suggested that the presence of a TPG qualification paper online and the swift introduction of TPG aligned courses in medical schools would streamline implementation challenges in the future. The researchers have also recommended the amendment of the TPG and the Medical Council of India (MCI) Code of Ethics Regulations, 2002, to provide better protection to RMPs from possible litigation occurring during telemedicine practice.

Keywords: telemedicine education; Telemedicine Practice Guidelines; tele-triage; cross-border consultation; medical ethics

$\mathrm{F}$ or most doctors, consultations over the telephone have never been a matter of novelty, and conventionally, several countries have had a framework for teleconsultation, including that for reimbursement. However, India lacked such a framework until recently. After the invocation of the Disaster Management Act, 2005, the Government of India on March 25, 2020, formally enabled registered medical practitioners (RMPs) to provide healthcare using telemedicine, and the guidelines were released by the Board of Governors in supersession of the Medical Council of India (MCI) (1). These Telemedicine Practice Guidelines (TPG) were enforced by the government by way of a gazette notification on May 14, 2020, as an amendment to the Indian Medical Council (Professional Conduct, Etiquette, Ethics) Regulations, 2002 (2). The TPG regulation requires all medical practitioners intending to practice telemedicine in India to take an online course and get certified within 3 years from the date of notification. In absence of such online course, the RMPs are expected to act in strict compliance with the guidelines, which can only be possible with effective training and familiarization with the TPG.

India has 1,062,398 allopathic doctors registered with the State Medical Councils/MCI as on December 
31, 2017. Assuming $80 \%$ availability, it is estimated that around 8.50 lakh doctors may be actually available for active service (3). Education and training (ET) of such a large number of doctors in India will always be a challenge. To address the issue of ET in telemedicine, a course called 'Train to Practice' was designed by the Telemedicine Society of India (TSI) (4). TSI is a registered notfor-profit entity in India and was established as a society in the year 2000. It has over 850 members and 11 state chapters in India. Its objectives are to promote ethical practice of Telemedicine and to be able to provide affordable and accessible healthcare to all (5). TSI devised the ET online course to train doctors in India to follow ethical and safe standards of practice of telemedicine as a means to increase their outreach and foster increased access to healthcare and take it to the last mile. This project commenced with voluntary efforts by the members of the society through online structured webinars within 2 weeks after the initial announcement in March 2020.

\section{Material and methods}

Microsoft Excel and SPSS 27 version were used to compile and statistically analyze the data. The ET course was designed to impart fundamental knowledge on telemedicine and was built around the TPG. With pandemic numbers on the rise and medical services under stress, it was felt necessary to help RMPs to undertake training and get familiar with the guidelines. The course had four basic modules followed by an interactive question and answer session.

The four modules included:

Module 1: Legal Aspects and Telemedicine-The first module discussed and highlighted the urgent points of consideration for a healthcare practitioner in practicing telemedicine. Keeping in mind regulatory changes and legal implications, this module was designed to provide handholding to healthcare practitioners, ensuring patient safety. Module 2: Clinical Aspects and Telemedicine-The second module married the concepts discussed in the first module and provided handholding with respect to the legal and ethical requirements of telemedicine and how to implement them from a clinician's perspective.

Module 3: Tele-Triage and Telemedicine-During COVID-19 crisis, tele-triage is an important area of focus and the first stop for virtual care (and in some cases also the last) for patients. This module helped in explaining to practitioners how tele-triage helps diagnose and direct non-critical cases to the next step in a person's care journey, in line with the current applicable laws.

Module 4: Technical Application and Telemedicine-The fourth and the final module conclusively tied in all the modules and presented to the healthcare practitioners the way forward, in adoption and incorporation of telemedicine into their regular practice. Simple solutions like
Skype, MS-Teams, Google-Meet, WhatsApp, and other freeware were highlighted for wider outreach and connect.

Each module was delivered as a live lecture of 20 to 30 minutes. A feedback form was included at the end of the course. Applied Cognition Systems as a collaborator in this endeavor provided its e-learning platform along with marketing and tech-support for delivery of the courses online. There were 35 training sessions that were conducted in 6 months from April to Sept 2020. Majority [80\%] were offered pro bono and [20\%] were paid. The course fee was granted from the educational organization; 2,946 RMPs took the course. The courses were initially conducted three to four times a week. Subsequently, it was reduced to once or twice a week mostly during weekends.

Ten faculty and eight supporting staff were contributing toward the delivery of the course, session wise. The minimum and maximum participants at any given time during a session varied from 16 to 276 . Total time spent for delivery of the course by the faculty was 140 hours. Four pro bono sessions were exclusively for Armed Forces medical officers and specialists.

Due to time constraints and planning, the ET course did not have a structured pre- and post-course assessment initially. After multiple webinars and understanding candidates' requirements, a pre- and post-course assessment was introduced. Once this was formulated, all participants were expected to take the assessment before enrolling.

The assessment questions were structured with multiple choice or true and false responses. The post-course assessment covered all important elements in the notified Telemedicine Guidelines. The pre- and post-course assessment question templates were not necessarily comparable. Objective of pre-assessment was to understand the candidates' level of basic understanding of the concepts of telemedicine. Post-assessment was to know if candidates had understood the essential elements in the TPG to practice safe telemedicine. In future, this would help understand improvement in knowledge imparted through the training modules.

The course also put together a very detailed 'Frequently Asked Questions' (FAQs) that went through several stages of iterations before being given out to the RMPs as a reference document that could be used at any time before they took the online test or later as a reference document. It was decided by the advisory board of TSI and the faculty to create two levels of certification - a certificate of attendance to the RMPs who merely attended the course and a certificate of completion for those who undertook the post-test assessment after the webinar and obtained at least $80 \%$ marks to show their proficiency for safe implementation of Telemedicine in their practice. Those who did not get the desired marks had a choice either to retake the training or re-attempt the post-course assessment after going through the FAQ's. The pre-course assessment 
had 25 questions, whereas the post-course assessment had 30 questions. The platform was provided by GYANIT and was used to conduct live interactive sessions along with offline self-study material, pre/post learning, Multiple Choice Question (MCQ) tests and assessments, FAQs, certification along with electronic fee collection and disbursement for paid courses. A total of 486 RMPs took part in the pre-course assessment but only 462 undertook the post-course assessment.

\section{Results}

The results of the pre- and post-course assessment are presented in Tables 1 and 2, and Table 3 depicts the responses of the five common questions. Frequency distribution was used for the statistical analysis of the pre- and post-assessment questionnaires.

Highlights of the results from pre-course assessmentMost candidates had clarity on basic concepts about telemedicine. Most RMPs (estimated at 97\%) understood that telemedicine was the exchange of medical information from one site to another via electronic communication; $97 \%$ also knew that a physician can prescribe medicine to a patient during a telephonic consultation but with certain restrictions; $87 \%$ said practice of telemedicine was legal in India; 84\% said doctor can provide basic health counseling to a patient over WhatsApp, telephone call, e-mail, and messages. Almost all (99\%) stated that doctors could charge fees when they did teleconsultations. When asked if doctors could practice telemedicine across states or countries, the answers were incorrect.

Lacunae in knowledge was demonstrated for the following questions, 'Can doctors be registered with a State Medical Council but not with the Medical Council of India', 24\% responded that this was not possible, whereas the TPG allows it; $15 \%$ felt that the RMPs can do cross border consultation from abroad, whereas TPG does not cover this aspect. Another area where many faltered was 'if doctors could advertise about their teleconsultations services'; 35\% felt they could advertise, whereas TPG does not permit it.

Questions in the post-course assessment with 90\% correct responses included:

- Tele-triage permitted over teleconsults.

- An RMP can prescribe medicines in a telemedicine consultation after getting sufficient medical information and as per the permissible drug lists.

- RMPs need to display their registration details to the patient before the commencement of a teleconsultation.

- In an emergency telemedicine consultation, it is best to recommend an in-person consult.

- mHealth or Mobile Health is a type of telemedicine.

- Recording of e-Consent.
- Electronic health record could add value to telemedicine practice.

- Telemedicine Practice Guidelines allow prescription of paracetamol.

In both pre- and post-course assessment, there were five common questions which have been listed in Table 3. In both the categories of responses, it was reaffirmed by the attendee RMPs that telemedicine can save time and travel costs (97\%): Hardware for Telemedicine included mobile phones, smart phones, and computers (99.80\%); Tele-triage is a component mainly of telemedicine (99.60\%).

Table 4 shows the overall performance results of preand post-course assessment. It indicates that candidates' performance improved after attending the course. Postcourse assessment showed that 97\% had obtained high or very high performance, indicating that the course was effective in imparting telehealth knowledge.

Questions from RMPs during interactive sessions are listed in Table 5. Queries were mostly related to legal requirements, drug prescription, remunerations for teleconsults, and logistics of setting up teleconsults. All doctors were not interested in taking up the post-test assessment; 1,259 certificates of attendance were issued but only 462 took the post-test assessment. Sponsored candidates were not interested in taking any assessment.

Monetary value of the course was calculated as Rs.3.74 million (or US\$ 51,233). Most of the course was subsidized or offered free of cost. There were seven paid or sponsored sessions from organizations or hospitals that paid the society Rs. 0.84 million (US \$ 11,507). The course was subsidized to the extent of Rs. 2.9 million (US \$39,726). The overall rating for the course was 4.7 / 5.

\section{Discussion}

COVID-19 pandemic is a global crisis. Social distancing, the worry about infectivity and associated morbidity, and mortality due to this unknown virus resulted in telehealth taking center stage. In the United States, one prediction estimated that more than 1 billion telehealth visits would take place (6). In India, the government in addition to the invocation of several emergency legislations (7) also ensured that telemedicine had legal backing and support from all stakeholders. TSI training programs started in April 2020 on a pro-bono service. Training, operational, and management staff opted in voluntarily. The training program therefore was heavily subsidized.

Historically, the first formal university accredited 4-week certificate course on Telehealth Technology was started with Anna University as early as 2003. Over the next 3 years, 150 candidates in six batches were trained. Unfortunately due to lack of employment opportunities, the course was discontinued (8). 
Table 1. Knowledge about Telemedicine Practice Guidelines-Pre-course assessment scores

\begin{tabular}{|c|c|c|}
\hline Pretest questions $(\mathrm{Q} 20)(n=486)$ & $n(\%)$ & $P$ value \\
\hline \multicolumn{3}{|l|}{ Telemedicine is the exchange medical information from one site to another via: } \\
\hline a. Written communication & $2(0.4)$ & $<0.001$ \\
\hline b. Print communication & $3(0.6)$ & \\
\hline c. Electronic communication & $469(96.5)$ & \\
\hline d. Verbal communication & $12(2.5)$ & \\
\hline \multicolumn{3}{|l|}{ Which of the following is not an example of telemedicine in India? } \\
\hline a. Physician sending $X$-rays to be reviewed by specialists outside hospital. & $\mathrm{I}(0.2)$ & $<0.001$ \\
\hline b. People in remote areas using communication systems to consult doctors in larger cities. & $13(2.7)$ & \\
\hline c. A doctor performing surgery in the operating room. & $459(94.4)$ & \\
\hline d. A doctor monitoring of health data from a database. & $13(2.7)$ & \\
\hline \multicolumn{3}{|l|}{ Is practice of telemedicine legal in India? } \\
\hline a. Yes & $473(97.3)$ & $<0.001$ \\
\hline b. No & $6(1.2)$ & \\
\hline c. Not sure & $7(1.4)$ & \\
\hline \multicolumn{3}{|l|}{ Can a physician prescribe medicine to a patient during a telephonic consultation? } \\
\hline a. Yes, freely. & $9(1.9)$ & $<0.001$ \\
\hline b. Yes, with certain restrictions. & $470(96.7)$ & \\
\hline c. Not without physical examination. & $\mathrm{I}(0.2)$ & \\
\hline d. It is illegal. & $6(1.2)$ & \\
\hline \multicolumn{3}{|c|}{$\begin{array}{l}\text { Can a doctor provide basic health counseling to a patient over WhatsApp, telephone call, e-mail, or } \\
\text { messages? }\end{array}$} \\
\hline a. Yes & $412(84.8)$ & $<0.001$ \\
\hline b. No & II (2.3) & \\
\hline c. Yes, but only as a follow-up consult. & $61(12.6)$ & \\
\hline d. Only if prior prescription says so. & $2(0.4)$ & \\
\hline \multicolumn{3}{|l|}{ Add on medications may be given during } \\
\hline a. Follow up sessions & $380(78.2)$ & $<0.001$ \\
\hline b. First consultation & $\mathrm{I}(0.2)$ & \\
\hline c. First or any consultation & $66(13.6)$ & \\
\hline d. Whenever the doctor feels & $39(8)$ & \\
\hline \multicolumn{3}{|l|}{ For effective video conferencing } \\
\hline a. Good and reliable connectivity is required at both the ends. & $480(98.8)$ & $<0.001$ \\
\hline b. Good connectivity of the platform will suffice. & $5(1.0)$ & \\
\hline c. Good connectivity at the patient end will suffice. & 0 & \\
\hline d. Connectivity issues are not so important. & $\mathrm{I}(0.2)$ & \\
\hline \multicolumn{3}{|l|}{ Doctors can practice telemedicine in India } \\
\hline a. True & $486(100)$ & $\mathrm{N} / \mathrm{A}$ \\
\hline b. False & 0 & \\
\hline \multicolumn{3}{|c|}{$\begin{array}{l}\text { Doctors registered with a State Medical Council but not with the Medical Council of India cannot } \\
\text { practice in another state }\end{array}$} \\
\hline a. True & $115(23.7)$ & $<0.001$ \\
\hline b. False & 37 I (76.3) & \\
\hline \multicolumn{3}{|c|}{ Patient-doctor relationship is established in face to face consultation but not during a tele-consultation } \\
\hline a. True & $28(5.8)$ & $<0.001$ \\
\hline b. False & $458(94.2)$ & \\
\hline \multicolumn{3}{|c|}{$\begin{array}{l}\text { The consent process in telemedicine consultation is implied when a patient seeks a consultations } \\
\text { himself }\end{array}$} \\
\hline a. True & $426(87.7)$ & $<0.001$ \\
\hline b. False & $60(12.3)$ & \\
\hline \multicolumn{3}{|l|}{ Doctors can prescribe medicines through teleconsultations } \\
\hline a. True & $484(99.6)$ & $<0.001$ \\
\hline b. False & $2(0.4)$ & \\
\hline
\end{tabular}


Table 1. (Continued)

\begin{tabular}{|c|c|c|}
\hline Pretest questions $(\mathrm{Q} 20)(n=486)$ & $n(\%)$ & P value \\
\hline \multicolumn{3}{|l|}{ Doctors can practice telemedicine for patients from outside India } \\
\hline a. True & $74(15.2)$ & $<0.001$ \\
\hline b. False & $412(84.8)$ & \\
\hline \multicolumn{3}{|c|}{$\begin{array}{l}\text { Care rendered to the patient for diagnosis and treatment through telemedicine should be the same as } \\
\text { face-to-face or in-person consultations }\end{array}$} \\
\hline a. True & $438(90.1)$ & $<0.001$ \\
\hline b. False & $48(9.9)$ & \\
\hline \multicolumn{3}{|l|}{ Doctors can advertise about their teleconsultation services } \\
\hline a. True & $172(35.4)$ & $<0.001$ \\
\hline b. False & $314(64.6)$ & \\
\hline \multicolumn{3}{|l|}{ Doctors can share patients details through social media with others } \\
\hline a. True & $9(1.9)$ & $<0.001$ \\
\hline b. False & $477(98.1)$ & \\
\hline \multicolumn{3}{|l|}{ Tele-triage can be } \\
\hline a. Carried out by specialists only & $3(0.6)$ & $<0.001$ \\
\hline b. Carried out by general practitioner (GP) doctors and specialists & $455(93.6)$ & \\
\hline c. Carried out only by GP doctors & $18(3.7)$ & \\
\hline d. Carried out by the application administrator & $10(2.1)$ & \\
\hline \multicolumn{3}{|l|}{ Tele-triage cannot be carried out without } \\
\hline a. Specific protocols that are need-based & $405(83.3)$ & $<0.001$ \\
\hline b. Tele-triage software & $43(8.8)$ & \\
\hline c. Specific devices like ultrasound and electro cardiogram machines & $15(3.1)$ & \\
\hline d. A land line phone & $23(4.7)$ & \\
\hline \multicolumn{3}{|l|}{ Doctors can charge fees when we do tele-consultations } \\
\hline a. True & 481 (99) & $<0.001$ \\
\hline b. False & $5(1)$ & \\
\hline \multicolumn{3}{|l|}{ In tele-triage } \\
\hline a. Needs pre-tele-triage activities & $10(2.1)$ & $<0.001$ \\
\hline b. Needs post-tele-triage activities & $7(1.4)$ & \\
\hline c. Needs A and B & $408(84)$ & \\
\hline d. Can be directly carried out & $61(12.6)$ & \\
\hline
\end{tabular}

*Z Proportion Test is used

* Overall the $P$ value is less than $0.00 I$. This result is significant at $p<0.05$

*N/A - Not applicable.

This first of its kind online training course in South Asia was received enthusiastically by doctors from different specialties. Despite variable levels of knowledge, basic understanding was revealed in the pre-course assessment. Telemedicine as an enabler was being practiced in India (as the MCI was silent) even before the current TPG came into force. Risks of practice were solely associated with the RMPs. This became evident when a complaint was filed by the Bangalore Dermatological Society in 2018 on an advertisement published in a newspaper by a technology health company inviting doctors to join their panel of online consultants. The Karnataka Medical Council advised doctors against engaging in online consultations stating that it runs contrary to the regulatory body's code of ethics, and the president of the society issued a statement that teleconsultation was detrimental to both patients and the doctor (9). However, the current TPG overcame such strictures, and now, the RMPs are better placed for practicing telemedicine.

Although majority of RMPs had reasonable knowledge regarding telemedicine in the pre-course assessment, most were not sure if cross state teleconsultations required registration or re-registration with the other states. Some were anxious to understand the legality of such consultations. In India, health being a state subject (10), all RMPs have to register with the State Medical Council even if they are on the national register. The guidelines clearly state that re-registration with another state is not necessary for conducting a teleconsult.

Disparity in delivery of healthcare in India has always been glaring. Telemedicine has been looked upon as a readymade solution providing cost-effective accessibility to reach remote areas and hence found support from the government (11). Telemedicine in India was promoted initially 
Table 2. Knowledge about Telemedicine Practice Guidelines-Post-course assessment scores

\begin{tabular}{|c|c|c|}
\hline Post questions $(Q 25)(n=462)$ & $n(\%)$ & $P$ value \\
\hline \multicolumn{3}{|l|}{ What is triage? } \\
\hline a. Something that includes patients from three age groups. & $\mathrm{I}(0.2)$ & $<0.001$ \\
\hline b. The third age (I6th century), when medicine was not organized. & $4(0.9)$ & \\
\hline c. Eliciting which patients have all three diseases of old-age. & 0 & \\
\hline d. Deciding which patients are to be treated first. & $457(98.9)$ & \\
\hline \multicolumn{3}{|l|}{ Tele-triage is } \\
\hline a. Viewing how to triage, on television. & $2(0.4)$ & $<0.001$ \\
\hline b. A way of triaging patients from a remote site. & $413(89.5)$ & \\
\hline $\begin{array}{l}\text { c. Ensuring triaging only via telephone asking if the routine patients seen in a primary care outpatient } \\
\text { department wish to see a specialist. }\end{array}$ & $38(8.2)$ & \\
\hline d. Asking if the routine patients seen in a primary care OPD wish to see a specialist & $9(1.9)$ & \\
\hline \multicolumn{3}{|l|}{ Is tele-triage is permitted in India? } \\
\hline a. No & $2(0.40)$ & $<0.001$ \\
\hline b. Only in super specialist opinions & 0 & \\
\hline c. Yes, as per a board of governors, Medical Council of India document 'Telemedicine Practice Guidelines'. & $460(99.6)$ & \\
\hline d. Only in villages as per Government of India & 0 & \\
\hline \multicolumn{3}{|l|}{ Tele-triage helps } \\
\hline a. The patient & $12(2.6)$ & $<0.001$ \\
\hline b. Reduces travel time & $2(0.4)$ & \\
\hline c. Saves the doctor from contagion & $\mathrm{I}(0.2)$ & \\
\hline d. All of the above & $447(96.8)$ & \\
\hline \multicolumn{3}{|l|}{ Tele-triage requires } \\
\hline a. Pre-tele-triage actions & II (2.4) & $<0.001$ \\
\hline b. Pre and post tele-triage actions & $384(83.1)$ & \\
\hline c. A rest period of 12 minutes after each post-triage action & $2(0.4)$ & \\
\hline d. Only b and c & $65(14.1)$ & \\
\hline \multicolumn{3}{|l|}{ What is the difference between phone and video-chat (VC) triage? } \\
\hline a. In a video chat, the doctor has to be well dressed. & $4(0.9)$ & $<0.001$ \\
\hline b. In a video chat, more clinical details can be accessed. & $7 \mid(15.4)$ & \\
\hline c. Phone chat is accessible to a large population. & I $(0.2)$ & \\
\hline d. All of the above. & $386(83.5)$ & \\
\hline \multicolumn{3}{|l|}{ A triage chart and checklist (pick the false answer) } \\
\hline a. Are useful to quickly and consistently triage patients? & $42(9.1)$ & $<0.001$ \\
\hline b. Tests that the telemedicine application is running. & $373(80.7)$ & \\
\hline c. Helps the doctor from forgetting certain points. & $31(6.7)$ & \\
\hline d. Ensure no important points are missed. & $16(3.5)$ & \\
\hline \multicolumn{3}{|l|}{ With respect to a triage chart (pick the false statement) } \\
\hline a. It is a guide and a tool. & $8(1.7)$ & $<0.001$ \\
\hline b. In spite of a triage chart, a doctor should also apply his knowledge. & $10(2.2)$ & \\
\hline c. Triage charts are fixed and never change globally. & $432(93.5)$ & \\
\hline d. Triage charts are updated as new knowledge emerges. & $12(2.6)$ & \\
\hline \multicolumn{3}{|l|}{ Who can practice telemedicine in India? } \\
\hline a. Anyone & 0 & $<0.001$ \\
\hline b. Registered medical practitioner (RMP) & $206(44.6)$ & \\
\hline c. Registered Medical Practitioner (RMP) who has undergone the required course & $255(55.2)$ & \\
\hline d. Any health worker independently & $\mathrm{I}(0.2)$ & \\
\hline \multicolumn{3}{|l|}{ Can an RMP advice patients outside the country? } \\
\hline a. Yes & $16(3.5)$ & $<0.001$ \\
\hline b. No & $384(83)$ & \\
\hline c. With necessary permissions & $52(11.3)$ & \\
\hline d. Maybe, under emergency & $10(2.2)$ & \\
\hline \multicolumn{3}{|l|}{ Can an RMP advise a patient over e-mail? } \\
\hline a. Yes & $370(80.1)$ & $<0.001$ \\
\hline b. No & $19(4.1)$ & \\
\hline c. Only in certain circumstances & $64(13.9)$ & \\
\hline d. Maybe, under emergency & $9(1.9)$ & \\
\hline \multicolumn{3}{|l|}{ Does a telemedicine consult always have to be in real time? } \\
\hline a. Yes, only real-time consults are permissible. & $78(16.9)$ & $<0.001$ \\
\hline b. No & $177(38.4)$ & \\
\hline c. Depends on context & $101(21.9)$ & \\
\hline d. No, with exceptions like emergency. & $106(22.8)$ & \\
\hline
\end{tabular}


$319(69.1)$

a. No, they are specifically excluded.
a. Telemedicine Practice Guidel

b. Yes

c. Only under supervision

d. Maybe

What must RMP exercise at all times?

a. Professional judgment

b. Professional misconduct

c. Medical negligence

d. Professional negligence

Does the RMP need to seek the consent of the patient before initiating a telemedicine consult?

a. Yes, always.

b. No, not required.

c. As the RMP deems fit.

d. Only when the caregiver is involved.

When can an RMP prescribe medicines in a telemedicine consultation?

a. When RMP has sought sufficient medical information and as per the permissible lists.

b. When patient asks for medicine.

c. There is no restriction.

d. Never.

Does an RMP need to communicate their registration details to the patient?

a. Not required.

b. Only when patient asks.

c. An RMP must communicate in consultation, all correspondence, including invoices.

d. Only on prescriptions.

What is a mandatory requirement under emergency telemedicine consults?

a. Must be referred to an in-person consult.

b. There should be no consultation.

c. No requirement.

d. Telemedicine consults in emergency conditions are illegal.

Telemedicine can be of the following type

a. Synchronous or real time

b All of these

c. Asynchronous or store and forward

d. Hybrid

mHealth or mobile health

a. Is not a type of telemedicine.

b. Is not a part of digital health.

c. Is not a part of telehealth.

d. Is also a type of telemedicine.

Telemedicine through video conferencing

a. Can provide better quality of care and trust.

b. Is technologically hassle free?

c. Is convenient time wise?

d. Doesn't have any unpleasant environment?

How to record eConsent?

a. All of these

b. Recording of verbal consent

c. Through short message service or mobile app

d. Through Email

Constraints of telemedicine include

a. Mis information

b. Excess information

c. Inconvenience of timing

d. All of these

Telemedicine practice will be more useful if

a. No records are maintained.

b. EHR systems are used.

c. Recording of the sessions are not done.

d. Recording of the sessions are not done.

Telemedicine Practice Guidelines allow prescription of

a. Morphine

b. Codeine

c. Paracetamol

c. Anti-cancer drug

461 (99.8)

I (0.2)

n (\%)

P value

$<0.001$

81 (17.5)

$56(12.1)$

$6(1.3)$

455 (98.6)

$3(0.6)$

$3(0.6)$

I $(0.2)$

407 (88)

$17(3.7)$

$4(0.9)$

34 (7.4)

460 (99.6)

0

$2(0.4)$

0

$5(I . I)$

5 (I.I)

$412(89.1)$

$40(8.7)$

432 (93)

I (0.2)

$20(4.3)$

9 (I.9)

$58(12.6)$

$397(86)$

I $(0.2)$

$6(1.3)$

33 (7.I)

$3(0.6)$

$9(1.9)$

$417(90.3)$

$428(92.7)$

$4(0.9)$

$25(5.4)$

5 (I.I)

45। (97.7)

9 (1.9)

I $(0.2)$

I (0.2)

87 (18.8)

5 (I.I)

14 (3)

356 (77.I)

$$
2 \text { (0.4) }
$$

$455(98.6)$

$3(0.6)$

$2(0.4)$

0

$<0.00$ I

" $Z$ Proportion Test is used

"Overall the $P$ value is less than 0.001 . This result is significant at $p<0.05$ 
Table 3. Common questions (5) responses for pre- and post-course assessment

\begin{tabular}{|c|c|c|c|}
\hline Pre-questions $(n=486)$ & n (\%) & Post-questions ( $n=462)$ & n (\%) \\
\hline \multicolumn{2}{|l|}{ Tele-triage is } & \multicolumn{2}{|l|}{ Tele-triage is a component mainly of } \\
\hline a. A component of information technology protocols & $6(1.2)$ & a. Telemedicine & $461(99.6)$ \\
\hline b. A component of telehealth & $447(92)$ & b. Cardiology & I (0.2) \\
\hline c. A component of a remote tele-audio device & $29(6)$ & c. Physiology & 0 \\
\hline d. A component of the call-center automated & $4(0.8)$ & d. Nephrology & 0 \\
\hline \multicolumn{4}{|l|}{ Electronic Private Automatic Branch Exchange } \\
\hline \multicolumn{2}{|l|}{ Tele-triage is (choose from following) } & \multicolumn{2}{|l|}{ Tele-triage can be done via } \\
\hline a. A software for medical care & $54($ I I.I) & a. Only phone, SMS and missed call & I (0.2) \\
\hline b. Is a telemedicine software for triage & 58 ( 11.9$)$ & b. Phone, short message service (SMS), Phone & $460(99.6)$ \\
\hline c. Triage done through remote means & $295(60.7)$ & app, video chat, and telemedicine applications & \\
\hline \multirow[t]{2}{*}{ d. Triage done on phone only } & $79(16.3)$ & c. A couriered letter & 0 \\
\hline & & d. Ist choice only & $\mathrm{I}(0.2)$ \\
\hline Telemedicine can & & \multicolumn{2}{|l|}{ Telemedicine can } \\
\hline a. Replace a doctor & 0 & a. Save time and travel costs & $450(97.5)$ \\
\hline b. Always better than face to face visit & $5(1.0)$ & b. Replace a doctor & I (0.2) \\
\hline c. Increase doctor patient rapport & $19(3.9)$ & c. Always better than face to face visit & $3(0.6)$ \\
\hline d. Save time and travel costs & $462(95.1)$ & d. Increase doctor patient rapport & $8(1.7)$ \\
\hline \multicolumn{2}{|l|}{ Hardware for telemedicine can include } & \multicolumn{2}{|l|}{ Hardware for telemedicine can include } \\
\hline a. Basic mobile phones & 0 & a. Basic mobile phones & 0 \\
\hline b. Smart phones & $4(0.8)$ & b. Smart phone & $\mathrm{I}(0.20)$ \\
\hline c. Computers & I (0.2) & c. All of these & $461(99.8)$ \\
\hline d. All of the above & $481(99)$ & d. Computer & 0 \\
\hline \multicolumn{2}{|l|}{ The media for teleconsultation may include } & \multicolumn{2}{|l|}{ The media for teleconsultation may include } \\
\hline a. Online meeting tools & $8(1.6)$ & a. Online meeting tools & $3(0.6)$ \\
\hline b. Social media like WhatsApp & $(0)$ & b. Social media like WhatsApp & I (0.2) \\
\hline c. Both $a$ and $b$ & $476(97.9)$ & c. Both of these & $458(99.2)$ \\
\hline d. None of these & $2(0.4)$ & d. None of these & 0 \\
\hline
\end{tabular}

Table 4. RMPs pre- and post-course overall assessment scores

\begin{tabular}{|c|c|c|}
\hline \multirow[t]{2}{*}{ Scores } & \multicolumn{2}{|c|}{$n(\%)$} \\
\hline & Pre-course assessment scores & Post-course assessment scores \\
\hline$<10$ (low performers) & $28(5.8)$ & $4(0.8)$ \\
\hline I I-20 (moderate performers) & $85(17.5)$ & II (2.4) \\
\hline $21-25$ (high performers) & $373(76.7)$ & $194(42)$ \\
\hline 26-30 (very high performers) & - & $253(54.8)$ \\
\hline
\end{tabular}

by the Indian Space Research Organization (ISRO) from 2001, and it helped with initial development and creation of infrastructure. ISRO's telemedicine initiatives (12) have been broadly divided into the following areas:

a. Providing telemedicine technology and connectivity between remote/rural hospital and super specialty hospitals for teleconsultation and treatment and training of doctors and paramedics.

b. Providing technology and connectivity for continuing medical education (CME) programs between medical colleges and postgraduate medical institutions/ hospitals.

c. Providing technology and connectivity for mobile telemedicine units for rural health camps, especially in areas of ophthalmology and community health. d. Providing technology and connectivity for disaster management support and relief.

To provide easy access to health information, the Ministry of Health Government of India has taken up projects like Integrated Disease Surveillance Project (IDSP), National Cancer Network (ONCONET), National Rural Telemedicine Network, National Medical College Network, and the Digital Medical Library Network (13). The Health Ministry, in 2005, set up a National Telemedicine Taskforce that was to address various issues. Issues included inter-operability, standards for data transmission, software, hardware, training, developing a national telemedicine grid, identifying players and projects involved with telemedicine, and evaluating their performance. Other areas covered included capacity and replicability 
Table 5. Common questions that were asked during interaction with RMPs

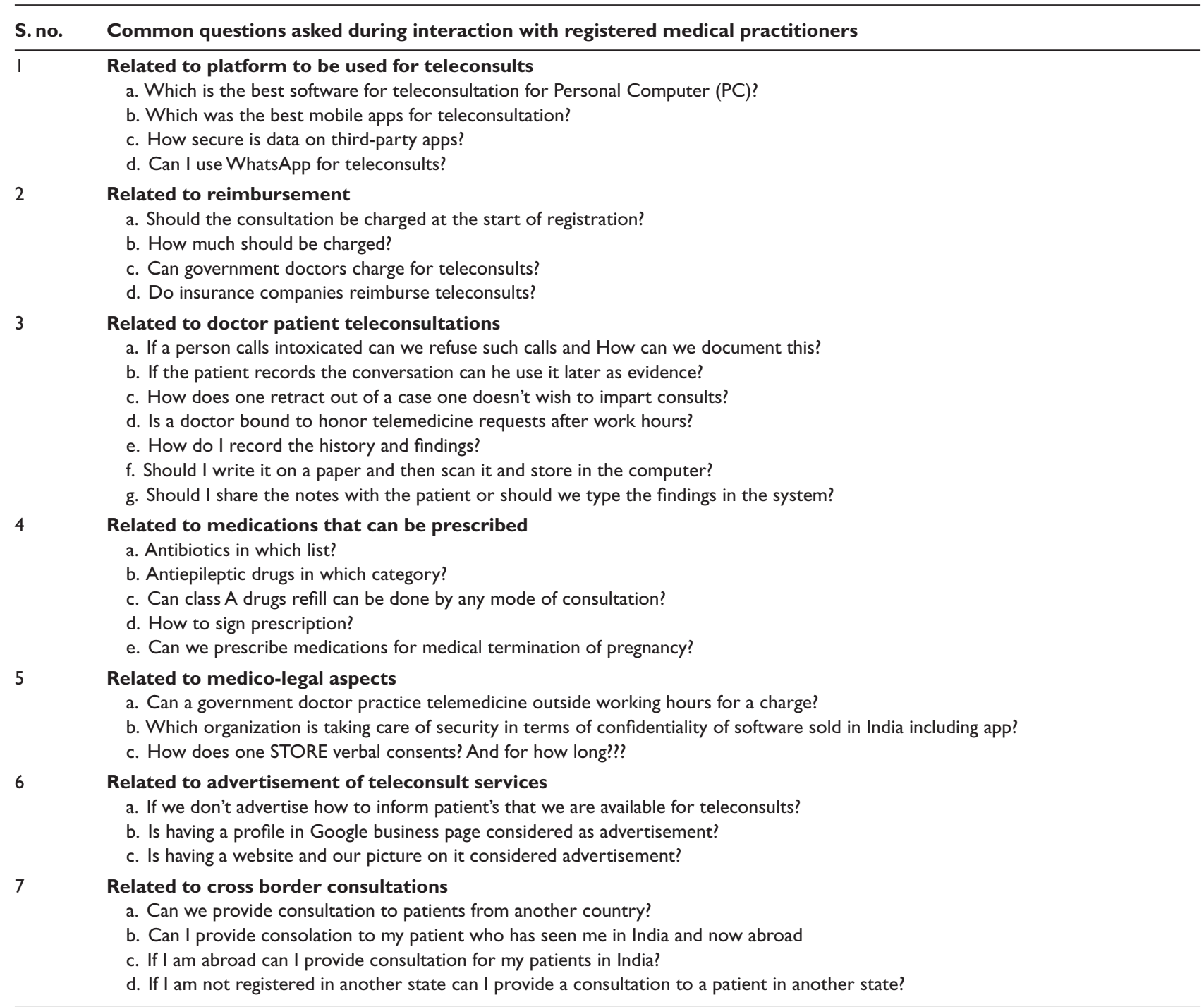

to network super specialty hospitals/medical colleges with district hospitals and/or Community Health Centers/ Primary Health Centers, to look at electronic medical records, to prepare national cancer telemedicine network, to enable telemedicine centers in teaching institutions to impart training to all government medical/ dental/nursing colleges in 3 years' time, to prepare curriculum and projects for CMEs through telemedicine, and to develop a national policy on 'telemedicine and telemedical education' (14). However not much happened and the efforts were fragmented. Then, TSI as a body in all these years had constantly pushed for the regulations and had made multiple representations to the Ministry of Health along with other similar societies. A study from Ernst \& Young and Indian Pharmaceutical Alliance indicates that telemedicine market in India will grow at a compounded annual growth rate of $31 \%$ for the period $2020-2025$ and reach USD 5.5 billion. However, it states that India will require a robust regulatory and governance framework that provides the right support for growth (15). COVID has resulted in a surge in global venture capital funding in digital health, and in 2020, it was $\$ 14.8$ billion with 637 deals, a 66\% increase over 2019 (16).

Safety of practice is an urgent requirement for ET in telemedicine for all medical and paramedical staff. TSI aims to be the key stakeholder for training of telehealth in India. It would be best for the National Medical Commission (NMC) to get an online test implemented on its website as soon as possible. This will ensure the seriousness of the policy-makers. TSI's own learnings would provide valuable training material to the NMC.

NMC's involvement would provide legality and reiterate the importance of such training. Most RMPs who attended and paid for the course attended all sessions 
and attempted pre- and post-course assessment MCQs. RMPs who did not attend less than $50 \%$ of the sessions had no interest in the assessments. Once the TPG is incorporated in the medical curriculum and the telemedicine certification is made mandatory, it would streamline implementation challenges. During this interregnum, TSI will provide the necessary support and ensure that all RMPs can get trained.

Sections in the current TPG document requiring clarity include data protection, privacy issues, standards for software and hardware, and medication lists for various specialties. Some office bearers of the Indian Medical Association, the largest non-profit society of RMPs in the world, have expressed concerns and apprehensions that the current guidelines do not protect the RMPs sufficiently against legal action. They have opined that there are many open-ended statements whose legal interpretation could jeopardize many practitioners (17). More dialogues with the Ministry of Health would be required regarding the proposal for inclusion of Telemedicine Practice Guidelines within the code of ethics of MCI in the regulation relese in the year 2002. It is hoped that the clarity on data protection and privacy issues would be addressed by the 'Data Protection Act', which is in draft stage (18).

\section{Conflict of Interest and funding}

Authors declare no potential conflict of interest.

\section{Acknowledgments}

The authors acknowledge the support received by the President of TSI - Maj. Gen. Dr. A.K. Singh (Retd.), President Elect, TSI - Col. Dr. Ashvini Goel (Retd.), Dr. Sashi Gogia, Founder President of S.A.T.H.I., Mr. Guriqbal Singh Jaiya, Past Director, SMEs Division, WIPO. Dr. Gunda Srinivas, Mr. Jai Ganesh Udayasankaran, Dr. Sai Praveen Haranath, and the team of GYANIT.

\section{References}

1. Telemedicine Practice Guidelines - enabling registered medical practitioners to provide healthcare using telemedicine. Appendix 5 of the Indian Medical Council (Professional Conduct, Etiquette and Ethics Regulation). Ministry of Health and Family Welfare. Government of India; 2020. Available from: https://www.mohfw. gov.in/pdf/Telemedicine.pdf [cited 18 January 2021].

2. Telemedicine guidelines released in India notified and gazetted. Med India. Empowering Better Health; 2020. Available from: https://www.medindia.net/news/healthinfocus/telemedicineguidelines-released-in-india-notified-and-gazetted-194980-1. htm [cited 18 January 2021].

3. The Minister of State in the Ministry of Health and Family Welfare. Parliament of India. Lok Sabha. House of the People. 2018. Available from: http://164.100.47.194/loksabha/Questions/ QResult15.aspx?qref=69322\&lsno=16 [cited 18 January 2021].
4. Shroff S. Universal access is the new normal. 'Train to Practice Telemedicine' certificate course. Telemedicine Society of India; 2020. Available from: https://tsi.org.in/learn/ [cited 18 January 2021].

5. Telemedicine Society of India. About TSI [Internet]. Lucknow: TSI. Available from: https://tsi.org.in/about/ [cited 10 March 2021].

6. US virtual care visits to soar to more than 1 billion. FORRESTER; 2020. Available from: https://go.forrester.com/ press-newsroom/us-virtual-care-visits-to-soar-to-more-than-1billion/ [cited 18 January 2021].

7. The Disaster Management Act, 2005. Act no. 53 of 2005. Legislative Department; 2005. Available from: http://legislative.gov. $\mathrm{in} / \mathrm{sites} /$ default/files/A2005-53.pdf [cited 11 January 2021]

8. e-Newsletter Sep 2020. TeleHealth NEWSLETTER. Vol. 1. Issue 1. Telemedicine Society of India, Tamil Nadu Chapter. 15 Sep 2020. Available from: https://tsitn.org/tsi-e-newslettersep2020/ [cited 18 January 2021].

9. Yasmeen A. KMC warns doctors against online consultations. The Hindu; 14 May 2019. Available from: https://www.thehindu. $\mathrm{com} /$ news $/$ national/karnataka/kmc-warns-doctors-against-online-consultations/article27130640.ece [cited 18 January 2021].

10. Wikepedia. State List [Internet]. Wikipedia: The Free Encyclopedia. Wikimedia Foundation; 28 January 2021. Available from: https://en.wikipedia.org/wiki/State_List [cited 10 March 2021].

11. Kasthuri A. Challenges to healthcare in India - the five A's. Indian J Community Med 2018 Jul-Sep; 43(3): 141-3. doi: 10.4103/ijcm.IJCM_194_18

12. Satyamurthy LS, Bhaskaranarayana A. Telemedicine: Indian Space Agency's (ISRO) Initiatives for Speciality Health Care Delivery to Remote \& Rural Population. Vision 2020 e-resource-for eyecare management worldwide. Available from: http://v2020eresource.org/content/files/remote_rural_population.htm [cited 18 January 2021].

13. Mishra SK, Kapoor L, Singh IP. Telemedicine in India: current scenario and the future. Telemed J E Health 2009 Jul-Aug; 15(6): 568-75. doi: 10.1089/tmj.2009.0059

14. Ministry of Health and Family Welfare, Government of India. Evolution of Telemedicine in India: Brief Summary [Internet]. New Delhi: Telemedicine Division, MOHFW, Govt. of India. Available from: https://www.nhm.gov.in/images/pdf/Telemedicine/Telemedicine.pdf [cited 10 March 2021].

15. Nair L. Why is a romance burgeoning between pharma and telehealth? PHARMA; 2020. Available from: https://www.ipa-india. org/wp-content/uploads/2020/11/media-coverages-20j.pdf [cited 18 January 2021].

16. HEALTHCARERADIUS. Venture funding in digital health sector up $66 \%$ globally, raises a record $\$ 14.8$ billion in 2020 [Internet]. HEALTHCARERADIUS; 8 January 2021. Available from: https://www.healthcareradius.in/business/27681-venture-funding-in-digital-health-sector-up-66-globally-raises-arecord-148-billion-in-2020 [cited 10 March 2021].

17. Business Standard. IMA seeks clear-cut guidelines on telemedication from MCI; 8 August 2018. Business Standard.[Internet]. Available from: https://www.business-standard.com/article/ pti-stories/ima-seeks-clear-cut-guidelines-on-telemedicationfrom-mci-118080801080_1.html [cited 10 March 2021].

18. Ministry of Electronics and Information Technology, Government of India. The Personal data protection bill; 2018 [Internet]. New Delhi: MEITY. Govt of India. Available from: https:// www.meity.gov.in/writereaddata/files/Personal_Data_Protection_Bill,2018.pdf [cited 10 March 2021]. 